\title{
STUDENT SELF-REGULATED LEARNING (SSRL) DALAM MATA KULIAH BAHASA INGGRIS PADA MAHASISWA TAHUN KEEMPAT JURUSAN BAHASA INGGRIS FKIP UNIVERSITAS MUHAMMADIYAH TANGERANG
}

\author{
Aidil Syah Putra ${ }^{1)}$, Nur Latifah ${ }^{1)}$ \\ ${ }^{1)}$ Universitas Muhammadiyah Tangerang, Tangerang, Indonesia \\ e-mail korespondensi : aidilsyahputra@umt.ac.id
}

diterima: 30 Juli 2018; direvisi: 14 Agustus 2018; disetujui: 01 September 2018

\begin{abstract}
Learning English is the activity for getting the knowledge about English. English should be learned since the beginner level to the advance level. There are some characteristics of students in learning process at classroom, such as they can pay attention to the teacher, and have purpose in learn. It is called Self-Regulated Learning. The design of this research was descriptive qualitative research. The setting of this research is FKIP Universitas Muhammadiyah Tangerang. There were five classes English Language Department at Fourth Year English Language Department. From five class, there were choosing 30 students for the participant. In choosing the participants the researcher used purposive sampling. The researcher used questionnaire to collect the data, and used peer debriefing to check the trustworthiness of the data. The result showed that process of self-regulated learning that used by students were goal setting, planning, self-motivation, attention control, self-monitoring, help-seeking, and self-evaluation. The highest of total value was goal setting 440 , self-monitoring with the total value 420 , self-evaluation with the total value 410 , self-motivation with the total value 392 , help-seeking with the total value 306, planning with the total value 305, and the least is attention control with the total value 300. The highest of total value of self-regulated learning was goal setting. So, it can be concluded that the fourth year students of FKIP Universitas Muhammadiyah Tangerang had applied the process of self-regulated learning, the most implemented process was goal setting and the least process was attention control.
\end{abstract}

Keywords: Self - Regulated Learning, Learning English

\section{PENDAHULUAN}

Bahasa adalah salah satu cara yang digunakan oleh orang untuk berkomunikasi dengan yang lain. Melalui bahasa, orang dapat menyampaikan gagasan, konsep, atau perasaan dalam pikiran mereka. Dengan orang bahasa juga dapat menerima informasi yang mereka butuhkan. Ada beberapa bahasa yang digunakan orang untuk berkomunikasi. Salah satu bahasanya adalah bahasa Inggris. Sehingga bahasa Inggris diajarkan di sekolah dan menjadi salah satu pelajaran di kelas, bahkan untuk orang Indonesia.

Di kelas, Bahasa Inggris harus dipelajari sejak tingkat pemula hingga tingkat mahir. Belajar Bahasa Inggris adalah kegiatan untuk mendapatkan pengetahuan tentang bahasa Inggris. Menurut Schunk [1] Pembelajaran Bahasa Inggris adalah perubahan perilaku yang bertahan lama, atau dalam kapasitas untuk berperilaku dengan cara tertentu, yang dihasilkan dari praktik atau bentuk pengalaman lain. Belajar melibatkan memperoleh dan memodifikasi pengetahuan, keterampilan, strategi, keyakinan, sikap, dan perilaku. Artinya, belajar bahasa Inggris adalah memperoleh dan memodifikasi pengetahuan dan perilaku. Selanjutnya, Chambers dkk [2] menyatakan bahwa Pembelajaran yang melibatkan perolehan pengetahuan, pemahaman dan keterampilan yang dipandang sebagai yang diinginkan dan penting atau berguna. Jadi, belajar melibatkan pemahaman dan keterampilan yang penting atau berguna. Ada empat keterampilan bahasa dalam belajar bahasa Inggris seperti mendengarkan, berbicara, membaca, dan menulis. Mereka didukung oleh beberapa keterampilan seperti tata bahasa, kosakata, ejaan, dan pelafalan yang juga diajarkan di kelas.
Berdasarkan pengetahuan dan pengalaman peneliti ketika mengajar di kelas, ada beberapa karakteristik siswa dalam proses pembelajaran di kelas. Pintrich dalam Schunk [3] mendeskripsikan self-regulated learning sebagai: "aktif, upaya untuk memantau, mengatur, dan mengendalikan kognisi, motivasi dan perilaku mereka, dipandu dan dibatasi oleh tujuan mereka dan fitur kontekstual dalam lingkungan". Itu berarti, belajar mandiri adalah pelajar menetapkan tujuan untuk belajar mereka dan berusaha untuk memantau, mengatur, dan mengendalikan kognisi, motivasi, dan perilaku mereka. Seperti mereka dapat memperhatikan guru, fokus pada pembelajaran, memiliki antusiasme dalam belajar, dan memiliki tujuan dalam belajar. Kemudian, terkadang mereka tidak bisa serius dalam proses belajar, dan juga tidak memiliki tujuan dalam pembelajaran, sehingga mereka tidak bisa mendapatkan poin dari guru.

Dalam pembelajaran di kelas, siswa tidak hanya menerima dari guru untuk mendapatkan sesuatu, tetapi juga mereka dapat mencari informasi dari yang lain. Ada beberapa siswa yang aktif di kelas, mampu mengendalikan cara belajar mereka, dan menilai penampilan mereka untuk mengatur motivasi, perilaku, dan konteks. Inilah yang disebut pembelajaran mandiri. Untuk mempromosikan pembelajaran mandiri di kelas, guru harus mengajar siswa proses yang diatur sendiri yang memfasilitasi pembelajaran. Menurut Zumbrunn [4] ada beberapa proses Self-Regulated Learning. Mereka adalah: Penetapan Sasaran, Perencanaan, Motivasi Diri, Kontrol perhatian, Pemantauan diri, pencarian Bantuan, dan Evaluasi diri. Dapat disimpulkan, untuk mencapai hasil maksimal untuk menjadi sukses siswa harus menetapkan tujuan dalam belajar, mereka juga memiliki 
perencanaan dan motivasi, mampu mengendalikan perhatian mereka dalam belajar, dan kemudian mereka dapat memantau dan mengevaluasi kemajuan mereka dalam belajar bahasa Inggris. .

Pembelajaran yang diatur sendiri terbukti menjadi hal yang penting. Siswa harus mengambil tanggung jawab untuk belajar mereka sendiri dan harus memainkan peran aktif dalam proses pembelajaran menggantikan teori instruksional, yang diberi peran reaktif daripada proaktif untuk pelajar. Selain itu siswa harus memiliki keinginan yang keras tanpa instruksi guru. Berdasarkan penjelasan di atas, peneliti tertarik untuk melakukan penelitian tentang Analisis Student Self-Regulated Learning (SSRL) dalam Pada Mata kuliah Bahasa Inggris di FKIP Universitas Muhammadiyah Tangerang

\section{METODE PENELITIAN}

Desain penelitian ini adalah penelitian kualitatif deskriptif. Menurut Gay [5] penelitian kualitatif adalah pengumpulan, analisis, dan interpretasi narasi komprehensif dan data visual untuk mendapatkan wawasan ke dalam fenomena tertentu yang menarik. Tujuan penelitian ini adalah untuk mengidentifikasi sejauh mana Student SelfRegulated Learning (SSRL) dalam Pembelajaran Bahasa Inggris yang digunakan oleh mahasiswa pada tahun keempat Jurusan Bahasa Inggris di FKIP Universitas Muhammadiyah Tangerang.

\section{HASIL DAN PEMBAHASAN}

Tujuan dalam penelitian ini adalah untuk mengetahui sejauhmana Student self-regulated learning (SSRL) dalam pembelajaran bahasa Inggris di FKIP Universitas Muhammadiyah Tangerang. Hasil penelitian Student SelfRegulated Learning (SSRL) dalam Belajar Bahasa Inggris diperoleh dengan menggunakan kuesioner. Kuesioner ini berisi tujuh proses yaitu penetapan tujuan, perencanaan, motivasi diri, kontrol perhatian, pemantauan diri, pencarian bantuan, dan evaluasi diri.

Jumlah mahasiswa adalah 30 siswa pada tahun keempat jurusan bahasa Inggris di FKIP Universitas Muhammadiyah Tangerang. Peneliti meminta semua mahasiswa untuk mengisi 25 pernyataan yang berisi lima pilihan kategori. Yaitu: selalu, biasanya, kadang-kadang, jarang, dan tidak pernah. Setelah mendapatkan data, peneliti mendapatkan hasil menunjukkan bahwa hampir semua proses dalam kuesioner digunakan oleh mahasiswa.

Hasil penelitian ini dapat dilihat pada tabel 1 . Berdasarkan tabel tersebut, dapat dijelaskan bahwa sebagian besar pembelajaran mandiri siswa adalah penetapan tujuan. Hal ini dapat dilihat dari total skor tanggapan siswa dalam penetapan tujuan adalah 440. Selanjutnya, pemantauan diri kedua. Total skor respon siswa dalam self-monitoring adalah 420. Kemudian evaluasi diri, total skor respon siswa adalah 410. Setelah itu motivasi diri, total skor respon siswa adalah 392. Maka paling tidak, membantu mencari, merencanakan, dan mengendalikan perhatian. Total skor respon siswa dalam pencarian bantuan adalah 306, dalam perencanaan 305, dan kontrol perhatian terakhir sekitar 300. Total skor semua proses belajar mandiri dalam belajar bahasa Inggris di prodi bahasa Inggris tahun keempat adalah 2573.

Tabel 1 Nilai Students Self-Regulated Learning

\begin{tabular}{llcc}
\hline No & $\begin{array}{l}\text { Proses Student } \\
\text { Self-Regulated }\end{array}$ & \multicolumn{2}{c}{ Total } \\
& Skor & \% \\
\hline 1 & Goal-Setting & 440 & 17.10 \\
\hline 2 & Self-Monitoring & 420 & 16.32 \\
\hline 3 & Self-Evaluation & 410 & 15.93 \\
\hline 4 & Self-Motivation & 392 & 15.24 \\
\hline 5 & Help-Seeking & 306 & 11.90 \\
\hline 6 & Perencanaan & 305 & 11.85 \\
\hline 7 & Attention contro. & 300 & 11.66 \\
\hline & Total & $\mathbf{2 5 7 3}$ & $\mathbf{1 0 0 \%}$ \\
\hline
\end{tabular}

Hasil dari penelitian ini juga dijelaskan dalam grafik berikut:

\section{Total Score}

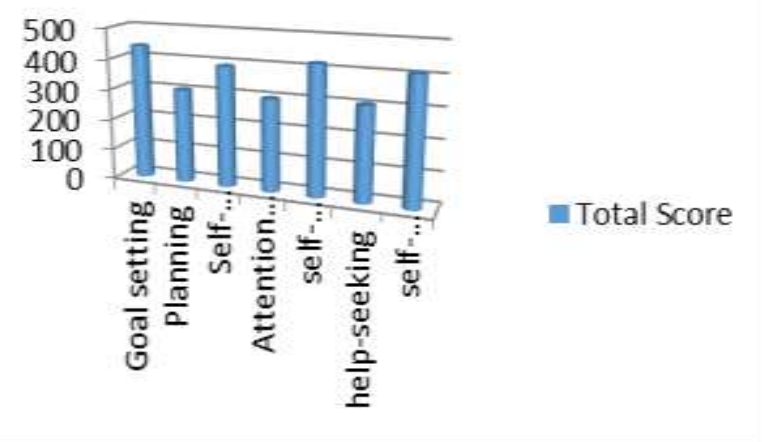

Gambar 1. Diagram Student Self-Regulated Learning

\section{Analisis Data}

Dalam analisis data, peneliti menggunakan skala likert. Kemudian, peneliti mengklasifikasikan jawaban siswa dari kuesioner pembelajaran mandiri siswa. Hasilnya dapat digambarkan sebagai berikut:

\section{Goal-Setting}

Skor tertinggi didapat dari kuesioner berada dalam penetapan tujuan (440). Hasil analisis data, dapat dilihat pada tabel 2 .

Berdasarkan tabel 2, dapat dijelaskan nomor pernyataan 1: "Saya telah menentukan target nilai disetiap mata kuliah bahasa Inggris" dengan skor 118. Ini berarti, bahwa siswa dapat menentukan poin apa yang harus dicapai dalam setiap mata kuliah bahasa Inggris. Skor tersebut juga menunjukkan bahwa mereka telah merencanakan bagaimana mencapai nilai dalam belajar bahasa Inggris. 
Tabel 2. The Total Skor Mahaisiwa dalam Goal-Setting

\begin{tabular}{llccc}
\hline Sub indikator & $\begin{array}{c}\text { Nomor } \\
\text { Soal }\end{array}$ & Skor & $\%$ \\
\hline 1. & Membuat target & 1 & 118 & 26.82 \\
\hline 2. & $\begin{array}{l}\text { Menentukan } \\
\text { Tujuan belajar }\end{array}$ & 2 & 119 & 27.05 \\
\hline $\begin{array}{l}\text { 3. } \\
\begin{array}{l}\text { Menggunakan } \\
\text { strategi yang } \\
\text { spesifik }\end{array}\end{array}$ & 3 & 109 & 24.77 \\
\hline \multicolumn{1}{c}{ Total } & 4 & 94 & 21.36 \\
\hline
\end{tabular}

Pernyataan nomer 2, "Saya menetapkan apa tujuan saya dalam belajar bahasa Inggris" dengan skor 119. Skor dalam pernyataan ini lebih tinggi dari pernyataan pertama, itu berarti, siswa cenderung memiliki perencanaan yang baik dalam belajar bahasa Inggris.

Pernyataan nomer 3, "Saya menggunakan strategistrategi belajar yang menurut saya mampu membuat saya bisa untuk mencapai target yang telah saya tetapkan" dengan skor 109. Dari skor ini, dapat dilihat bahwa mahasiswa tidak membuat target dan membuat rencana, tetapi para siswa juga menggunakan beberapa strategi untuk mencapai tujuan mereka.

Pernyataan nomer 4, "Saya meniru cara belajar teman-teman yang nilainya lebih tinggi dari saya agar bisa mencapai tujuan belajar yang telah saya tetapkan" dengan skor 94. Pernyataan terakhir dalam penetapan tujuan, menunjukkan bahwa siswa menggunakan beberapa strategi yang diambil dari teman mereka yang mendapat nilai bagus.

Berdasarkan penjelasan di atas, dapat disimpulkan bahwa total skor siswa yang memiliki penetapan tujuan memiliki tertinggi (119), dan lebih rendah (94). Artinya, siswa telah menerapkan pembelajaran self-regulated dalam proses penetapan tujuan. Hal ini ditunjukkan oleh jawaban siswa yang menyatakan mereka telah menetapkan rencana atau target dalam pembelajaran, setelah itu mereka telah memutuskan tujuan pembelajaran dan kemudian mereka juga menggunakan strategi mereka dalam belajar untuk mencapai tujuan mereka dalam belajar bahasa Inggris.

\section{Self-Monitoring}

Kemudian, diikuti dengan pemantauan diri, juga digunakan oleh mahasiswa dengan skor (420). Hasil analisis data dapat dilihat pada tabel 3 .

Tabel 3 Total Nilai Mahasiswa dalam Self-Monitoring

\begin{tabular}{cccc}
\hline \multirow{2}{*}{ Sub indikator } & $\begin{array}{c}\text { Nomor } \\
\text { Soal }\end{array}$ & Skor & $\%$ \\
\hline $\begin{array}{l}\text { 1. Mampu mengevaluasi } \\
\text { pembelajaran mereka } \\
\text { sendiri }\end{array}$ & 22 & 96 & 23.41 \\
\cline { 2 - 4 } & 23 & 104 & 25.37 \\
\cline { 2 - 4 } & 24 & 101 & 24.63 \\
\hline \multicolumn{1}{c}{ Total } & & $\mathbf{4 1 0}$ & $\mathbf{1 0 0} \%$
\end{tabular}

Pernyataan momer 16, "Saya mampu melihat tujuan saya dalam belajar bahasa Inggris" with the score 107. Dengan demikian, skor dalam pernyataan ini lebih tinggi dari pernyataan pertama, dapat dilihat siswa tahu apa tujuan mereka dalam setiap mata kuliah Bahasa Inggris.

Pernyataan nomer 17, "Saya mampu mengatur rencana kedepan untuk mencapai tujuan saya dalam belajar bahasa Inggris" dengan skor 105. Dari skor ini, dapat dilihat bahwa tidak hanya melihat tujuan dan kemampuan mereka dalam belajar bahasa Inggris, para siswa juga mengatur rencana untuk mencapai tujuan mereka dalam belajar bahasa Inggris.

Pernyataan nomer 18, "Saya mampu mengamati gambaran kemajuan belajar saya dalam pelajaran bahasa Inggris" dengan skor 102. Pernyataan terakhir dalam pemantauan diri, menunjukkan bahwa siswa dapat mengamati kemajuan mereka dalam belajar bahasa Inggris.

Berdasarkan penjelasan di atas, dapat disimpulkan bahwa total skor siswa yang memiliki self-monitoring dalam belajar bahasa Inggris memiliki tertinggi (107), dan lebih rendah (102). Itu berarti, para siswa telah memantau apa yang mereka lakukan untuk tujuan dalam belajar bahasa Inggris. Hal ini dapat dilihat oleh respon siswa yang menyatakan bahwa mereka dapat melihat kemampuan dan tujuan mereka dalam belajar bahasa Inggris, sehingga mereka juga dapat memantau kemajuan mereka dalam belajar bahasa Inggris.

\section{Self-Evaluation}

Setelah itu, proses selanjutnya yang dimiliki mahasiswa adalah evaluasi diri dengan skor (410). Hasil analisis data dapat dilihat pada tabel 4 .

Tabel 4 Total Nilai Mahasiswa dalam Self-Evaluation

\begin{tabular}{lccc}
\hline \multirow{2}{*}{ Sub indikator } & $\begin{array}{c}\text { Nomor } \\
\text { Soal }\end{array}$ & Skor & $\%$ \\
\hline $\begin{array}{l}\text { Memantau } \\
\text { kemajuan } \\
\text { mereka }\end{array}$ & 15 & 106 & 25.23 \\
\cline { 2 - 4 } & 16 & 107 & 25.48 \\
\hline & 17 & 105 & 25.00 \\
\hline & Total & 102 & 24.29 \\
\hline & & $\mathbf{4 2 0}$ & $\mathbf{1 0 0} \%$
\end{tabular}

Berdasarkan tabel 4, dapat dijelaskan bahwa pernyataan nomor 22, "Saya mampu menilai sejauh mana kemampuan saya dalam belajar bahasa Inggris" dengan skor 96. Ini berarti, para mahasiswa dapat melihat seberapa jauh kemampuan mereka dalam belajar, dan skor menunjukkan bahwa mereka dapat mengevaluasi kemampuan mereka selama belajar.

Pernyatan nomer 23, "Saya mampu menilai sejauh mana tujuan saya dalam belajar bahasa Inggris" dengan skor 104. Dengan demikian, bukan hanya kemampuan mereka, tetapi skor dalam pernyataan ini juga menunjukkan 
bahwa mereka juga dapat mengevaluasi tujuan mereka dalam belajar bahasa Inggris.

Pernyataan nomer 24, "Saya mampu menilai perubahan apa yang terjadi setelah saya menggunakan strategi-strategi belajar saya dalam pelajaran bahasa Inggris" dengan skor 101. Jadi, setelah mahasiswa mengevaluasi kemampuan mereka dan tujuan dalam belajar, skor dalam pernyataan ini menunjukkan bahwa mahasiswa mampu mengevaluasi perubahan setelah menerapkan strategi mereka dalam belajar bahasa Inggris.

Pernyataan nomer 25, "Saya mampu membuat perubahan dalam mencapai tujuan belajar saya” dengan skor 109. Ini berarti, skor dalam pernyataan terakhir dalam evaluasi diri menunjukkan bahwa mahasiswa mampu membuat perubahan untuk mencapai tujuan mereka dalam belajar bahasa Inggris.

Berdasarkan penjelasan di atas, dapat disimpulkan bahwa total skor mahasiswa yang memiliki evaluasi diri dalam belajar bahasa Inggris memiliki tertinggi (109), dan lebih rendah (96). Dapat dilihat, mahasiswa telah menerapkan pembelajaran self-regulated dalam evaluasi diri. Hal ini ditunjukkan oleh respon mahasiswa yang menyatakan mereka telah mengevaluasi apa yang terjadi dalam kemajuan mereka setelah mereka menggunakan strategi dalam belajar, dan mereka juga mampu melakukan perubahan untuk mencapai hasil yang maksimal dalam belajar bahasa Inggris.

\section{Self-Motivation}

Proses selanjutnya dalam self-regulated yang dimiliki mahasiswa adalah motivasi diri dengan skor (392). Hasil analisis data dapat dilihat pada tabel 5 .

Tabel 5. Total Nilai Mahasiswa dalam Self-motivation

\begin{tabular}{cccc}
\hline \multicolumn{1}{c}{ Sub indikator } & $\begin{array}{c}\text { Nomor } \\
\text { Soal }\end{array}$ & Skore & $\%$ \\
\hline $\begin{array}{l}\text { 1. Gunakan satu atau } \\
\text { lebih strategi }\end{array}$ & 8 & 95 & 24.23 \\
\hline $\begin{array}{l}\text { 2. Bertahan melalui } \\
\text { tugas belajar yang } \\
\text { sulit }\end{array}$ & 9 & 87 & 22.20 \\
\cline { 2 - 4 } & 10 & 111 & 28.31 \\
\hline Total & & $\mathbf{3 9 2}$ & $\mathbf{1 0 0 \%}$ \\
\hline
\end{tabular}

Berdasarkan tabel 5, dapat dijelaskan bahwa pernyataan nomor 8, "Saya selalu membaca buku bahasa Inggris ketika ada waktu senggang agar saya bisa berbahasa Inggris dengan lancar" with the score 95. Artinya, dalam pernyataan ini menunjukkan bahwa salah satu strategi yang dapat dilakukan siswa adalah membaca buku berbahasa Inggris, dapat memotivasi diri untuk lebih lancar dalam berbahasa Inggris.

Pernyataan nomor 9, "Saya lebih suka saat dosen memberi tugas yang sulit agar saya lebih giat lagi untuk belajar bahasa Inggris" dengan nilai 87. Dengan demikian di samping itu, ada juga di antara mereka yang suka ketika dosen mereka memberikan tugas yang sulit, mungkin itu dapat memotivasi diri untuk lebih aktif dalam belajar bahasa Inggris.

Pernyataan nomor 10, "Saya selalu bersemangat untuk mencari arti dari kata-kata yang baru saya temukan agar kosa kata dalam bahasa Inggris saya bisa bertambah" dengan skor 111. Skor dalam pernyataan ini lebih tinggi dari pernyataan sebelumnya, itu berarti, para siswa antusias untuk melihat makna kata baru yang mereka temukan, itu karena dapat meningkatkan kosakata mereka dalam belajar bahasa Inggris.

Pernyataan nomer 11, "Saya selalu berusaha untuk mencari sendiri ketika mendapat tugas yang sulit dari dosen, agar saya bisa lebih paham lagi dengan bahasa Inggris" dengan skor 99. Sementara itu, mereka juga mampu membuat tugas sendiri yang diberikan oleh dosen mereka, itu ditunjukkan dalam pernyataan ini. Karena dengan cara ini, para siswa dapat memotivasi diri untuk bersemangat dalam belajar bahasa Inggris.

Berdasarkan penjelasan di atas, dapat disimpulkan bahwa total skor siswa yang memiliki motivasi diri dalam belajar bahasa Inggris memiliki tertinggi (111), dan lebih rendah (87). Artinya, banyak siswa yang menerapkan pembelajaran self-regulated dalam motivasi diri. Hal ini dapat dilihat oleh jawaban mahasiswa bahwa mereka mampu memotivasi diri dalam belajar. Hal ini ditunjukkan oleh para mahasiswa menjawab bahwa mereka selalu melakukan tugas yang sulit dengan sendirinya yang diberikan oleh dosen mereka, karena dapat membuat mereka menjadi lebih aktif dalam belajar bahasa Inggris.

\section{Help-Seeking}

Selanjutnya, belajar mandiri yang dimiliki mahasiswa adalah mencari bantuan dengan skor (306). Ini termasuk dalam skor rendah. Hasil dari analisis data, dapat dilihat pada tabel berikut:

Tabel 6. Total Nilai Mahasisiwa dalam Help-Seeking

\begin{tabular}{|c|l|l|c|}
\hline Sub indikator & $\begin{array}{l}\text { Nomor } \\
\text { Soal }\end{array}$ & Skore & $\%$ \\
\hline \multirow{2}{*}{$\begin{array}{c}\text { 1. Cari bantuan } \\
\text { dari yang lain }\end{array}$} & 19 & 98 & 32.03 \\
\cline { 2 - 4 } & 20 & 99 & 32.35 \\
\cline { 2 - 4 } & 21 & 109 & 35.62 \\
\hline \multicolumn{2}{|l}{ Total } & $\mathbf{3 0 6}$ & $\mathbf{1 0 0 \%}$ \\
\hline
\end{tabular}

Berdasarkan tabel 6, dapat dijelaskan bahwa pernyataan nomor 19, "Saya selalu bertanya kepada dosen apabila ada pelajaran bahasa Inggris yang kurang saya pahami" dengan skor 98. Artinya, para siswa harus memiliki inisiatif untuk bertanya kepada dosen mereka jika mereka tidak mengerti tentang pelajaran.

Pernyataan nomer 20, "Saya suka mencari tahu tentang materi-materi bahasa Inggris di perpustakaan untuk saya baca agar saya bisa lebih lancar berbahasa Inggris" dengan skor 99. Ini berarti, mereka juga lebih aktif untuk membaca materi bahasa Inggris di perpustakaan agar lebih fasih berbahasa Inggris. 
Pernyataan nomer 21, "Ketika saya tidak masuk kuliah, saya selalu meminjam catatan teman dan bertanya apabila ada pelajaran bahasa Inggris yang tidak saya pahami" with the score 109. Nilai ini dalam pernyataan ini lebih tinggi daripada pernyataan sebelumnya, itu berarti, para siswa tidak hanya diam jika mereka tidak datang dalam proses belajar, tetapi mereka ingin bertanya dan meminjam buku catatan teman mereka.

Berdasarkan penjelasan di atas, dapat disimpulkan bahwa total skor mahasiswa yang memiliki bantuan mencari dalam belajar bahasa Inggris memiliki tertinggi (109), dan lebih rendah (98). Dapat dilihat beberapa siswa yang memiliki proses ini dalam pembelajaran mandiri. Hal ini ditunjukkan oleh respon mahasiswa yang menyatakan sedikit mahasiswa yang memiliki bantuan mencari belajar, karena beberapa dari mereka yang bersedia bertanya kepada dosen mereka jika mereka menemukan kesulitan dalam tugas. Itu bisa terjadi karena mungkin mereka merasa malu untuk bertanya dari lingkungan sosial, sehingga mereka hanya diam saja.

\section{Perencanaan}

Setelah itu yang terakhir dari proses yang memiliki siswa berencana dengan skor (305). Hasil dari analisis data, dapat dilihat pada tabel berikut:

Tabel 7. Total Nilai Mahasiswa dalam Perencanaan

\begin{tabular}{lllll}
\hline Sub indikator & $\begin{array}{l}\text { Nomor } \\
\text { Soal }\end{array}$ & Skor & $\%$ \\
\hline 1. & $\begin{array}{l}\text { Tetapkan tujuan } \\
\text { untuk tugas belajar }\end{array}$ & 5 & 101 & 33.11 \\
\hline $\begin{array}{l}\text { 2. } \\
\begin{array}{l}\text { Menetapkan } \\
\text { Strategi }\end{array}\end{array}$ & 6 & 109 & 35.74 \\
\hline 3. & $\begin{array}{l}\text { Menentukan } \\
\text { Waktu }\end{array}$ & 7 & 95 & 31.15 \\
\hline \multicolumn{3}{r}{ Total } & $\mathbf{3 0 5}$ & $\mathbf{1 0 0 \%}$ \\
\hline
\end{tabular}

Berdasarkan tabel 7, dapat dijelaskan bahwa pernyataan nomor 5, "Saya sudah menyusun rencana tujuan belajar yang baik agar bisa menyelesaikan tugas bahasa Inggris" dengan skor 101. Dalam pernyataan ini para mahasiswa memiliki rencana yang baik untuk menyelesaikan tugas mereka dalam belajar bahasa Inggris.

Pernyataan nomer 6, "Saya menetapkan strategi dalam belajar bahasa Inggris agar bisa mencapai tujuan belajar" dengan skor 109. Selanjutnya, tidak hanya memiliki rencana yang baik, para siswa juga menetapkan strategi mereka dalam belajar bahasa Inggris untuk mencapai tujuan mereka.

Pernyataan nomer 7, "Saya selalu menentukan waktu untuk belajar bahasa Inggris saat dirumah agar bisa mencapai hasil belajar yang baik" dengan skor 95. Dengan demikian, para siswa telah menentukan waktu untuk belajar untuk mendapatkan hasil maksimal dalam belajar bahasa Inggris.

Berdasarkan penjelasan di atas, dapat disimpulkan bahwa total skor siswa yang memiliki perencanaan dalam belajar bahasa Inggris memiliki skor tertinggi (109), dan lebih rendah (95). Hal ini dapat dilihat sedikit dari mereka yang memiliki perencanaan dalam pembelajaran, karena mereka belum mengatur perencanaan dan mengatur waktu untuk belajar.

\section{Attention control}

Proses terakhir belajar mandiri adalah kontrol perhatian dengan skor (300). Proses ini skornya paling rendah. Hasil analisis data dapat dilihat pada tabel berikut:

Tabel 8 Total Nilai Mahasiswa dlm Attention Control

\begin{tabular}{|c|c|c|c|}
\hline Sub indikator & $\begin{array}{l}\text { Nomor } \\
\text { Soal }\end{array}$ & Skor & $\%$ \\
\hline \multirow{3}{*}{$\begin{array}{l}\text { 1. Membersihkan pikiran } \\
\text { yang mengalihkan } \\
\text { perhatian }\end{array}$} & 12 & 102 & 34.00 \\
\hline & 13 & 94 & 31.33 \\
\hline & 14 & 104 & 34.67 \\
\hline Total & & 300 & $100 \%$ \\
\hline
\end{tabular}

Berdasarkan tabel 8, dapat dijelaskan bahwa pernyataan nomor 12, "Saya tidak mempedulikan apapun gangguan yang datang pada saat belajar bahasa Inggris" dengan skor 102. Ini berarti, siswa tidak mudah dipengaruhi selama belajar, mereka juga tidak peduli apa masalah yang terjadi di sekitarnya.

Pernyataan nomer 13, "Saya tidak suka berbicara dengan teman pada saat belajar bahasa Inggris" dengan skor 94. Dari skor ini dapat dilihat, bahwa mahasiswa serius dalam belajar, mereka tidak berbicara dengan teman mereka selama belajar.

Pernyataan nomer 14, "Saya selalu fokus pada saat belajar bahasa Inggris dikelas" dengan skor 104. Pernyataan terakhir dalam kendali perhatian menunjukkan bahwa mahasiswa serius dan fokus dalam belajar bahasa Inggris.

Berdasarkan penjelasan di atas, dapat disimpulkan bahwa skor total mahasiswa yang memiliki kontrol perhatian dalam belajar bahasa Inggris memiliki tertinggi (104), dan lebih rendah (94). Ini adalah proses yang paling tidak dimiliki oleh mahasiswa dalam belajar bahasa Inggris. Dapat dilihat paling tidak mahasiswa yang memiliki perhatian dalam belajar. Mereka masih tidak bisa fokus dalam belajar, mereka juga masih kepincut di sekitar.

\section{Pembahasan}

Self-regulated adalah proses siswa untuk menjadi aktif, berusaha untuk memantau, mengatur, dan mengendalikan perhatian, motivasi dan perilaku mereka, dipandu dan dibatasi oleh tujuan mereka dan fitur kontekstual di lingkungan. Ada tujuh proses yang mendukung pembelajaran mandiri, yaitu: Penetapan Sasaran, Perencanaan, Motivasi Diri, Kontrol Perhatian, Pemantauan Diri, Pencarian Bantuan, dan Evaluasi Diri.

Peneliti menggunakan 25 item kuesioner untuk mendapatkan data yang diperlukan untuk mengetahui sejauh mana siswa self-regulated learning (SSRL) dalam belajar bahasa Inggris di FKIP Universitas Muhammadiyah 
Tangerang. Dari analisis data, dapat digambarkan sebagai berikut:

\section{1) Goal Setting}

Dalam penetapan tujuan, jawaban mahasiswa dari pernyataan dalam kuesioner sebagian besar menghasilkan skor tinggi dengan total skor 440. Hal ini karena siswa telah menetapkan tujuan mereka dan memiliki target dalam belajar bahasa Inggris, dan kemudian mereka juga menggunakan strategi mereka dalam belajar untuk mencapai tujuan dalam belajar bahasa Inggris.

\section{2) Self-monitoring}

Dalam pemantauan diri, peneliti menemukan hasil mahasiswa hampir dengan penetapan tujuan dengan skor 420. Hal ini dapat terjadi karena siswa telah memantau apa tujuan mereka dalam belajar bahasa Inggris. Mereka dapat melihat kemampuan dan tujuan mereka dalam belajar bahasa Inggris, sehingga mereka juga dapat memantau proses mereka dalam belajar bahasa Inggris.

\section{3) Self-evaluation}

Dalam evaluasi diri, peneliti mendapat skor jawaban mahasiswa yang berbeda dengan self-monitoring, karena total skor 410. Dalam belajar bahasa Inggris, para mahasiswa telah mengevaluasi apa yang terjadi dalam kemajuan mereka setelah mereka menggunakan strategi mereka dalam belajar, mereka juga mampu melakukan perubahan dalam mencapai tujuan mereka, dan kemudian mereka juga dapat mengevaluasi bagaimana tujuan mereka selama belajar.

\section{4) Self-motivation}

Dalam proses ini, peneliti menemukan hasil jawaban mahasiswa dari kuesioner dengan skor 392. Hal ini dapat dilihat, siswa mampu memotivasi diri dalam belajar. Beberapa dari mereka tidak menggunakan strategi untuk membuat semangat untuk diri mereka sendiri dalam pembelajaran, tetapi juga banyak dari mereka senang untuk membuat tugas yang sulit yang diberikan oleh dosen mereka sendiri, karena itu dapat membuat mereka menjadi lebih aktif dalam belajar bahasa Inggris.

Ini didukung oleh pengaturan diri siswa menurut Merriam [6] belajar membuat catatan di setiap pelajaran strategi siswa yang diidentifikasi dalam literatur sebagai mempromosikan pengaturan diri, seperti motivasi untuk terlibat dengan tugas, dan kegiatan perencanaan.

\section{5) Help-seeking}

Proses selanjutnya dari pembelajaran mandiri adalah pencarian bantuan. Peneliti menemukan hasil jawaban siswa dari kuesioner dengan skor 306. Dapat dilihat, beberapa dari mereka yang bersedia bertanya kepada dosen mereka jika mereka menemukan kesulitan dalam tugas. Itu bisa terjadi karena mungkin mereka merasa malu untuk bertanya dari masyarakat mereka. Ini didukung oleh pernyataan Zimmerman [7] mencari bantuan sosial adalah strategi yang paling sering diamati dan yang paling sering dilaporkan oleh para peserta dalam penelitian ini. Ini mengacu pada mencari bantuan teman sebaya dan mencari bantuan guru ketika mereka menemukan kesulitan dalam tugas.

\section{6) Perencanaan}

Dalam perencanaan, peneliti menemukan hasil jawaban siswa dengan skor 305. Sedikit dari mereka yang memiliki perencanaan dalam pembelajaran, mereka tidak mengatur perencanaan mereka dalam belajar dan mengatur waktu untuk belajar. Mereka juga tidak mengatur perencanaan mereka tujuan dalam belajar. Ini didukung oleh Wang [8] untuk mendapatkan nilai yang lebih tinggi dalam menulis tugas, ia sering memeriksa waktu yang tersisa.

7) Attention control

Pernyataan ini adalah skor rendah yang diperoleh peneliti dari kuesioner dengan skor 300. Hal ini dapat terjadi karena dalam belajar mahasiswa tidak memiliki perhatian untuk belajar dan mereka juga tidak dapat fokus dalam belajar bahasa Inggris.

Penelitian yang dilakukan Yulinawati, Hartati dan Sawitri (2006) menemukan bahwa dengan student selfregulated learning mahasiswa dapat mengatur diri mereka sendiri dengan cukup baik. Mahasiswa melakukan dengan cara atau gaya sendiri dalam mengatur waktu.

Berdasarkan uraian di atas, peneliti menyimpulkan bahwa student self-regulated learning mahasiswa dalam belajar bahasa Inggris pada tahun keempat Jurusan Bahasa Inggris di FKIP Universitas Muhammadiyah Tangerang melalui semua proses, ditemukan sebagian besar proses oleh yang diterapkan mahasiswa adalah goal setting dengan total 440. Dikatakan oleh Zumbrunn [4] strategi yang diatur sendiri dapat meningkatkan pembelajaran siswa dapat sangat membantu mereka mempersiapkan diri untuk menantang tugas belajar dan mencapai tujuan mereka dalam belajar bahasa Inggris.

\section{SIMPULAN}

Dari hasil penelitian, yang paling tinggi dari skor total student self-regulated learning adalah penetapan tujuan. Jadi, dapat disimpulkan bahwa mahasiswa semester keempat Jurusan Bahasa Inggris di FKIP Universitas Muhammadiyah Tangerang telah menerapkan proses pembelajaran mandiri dan proses yang diterapkan sebagian besar oleh siswa adalah penetapan tujuan. Itu karena, mereka telah menetapkan rencana atau target dalam pembelajaran, dan kemudian mereka juga menggunakan strategi mereka dalam belajar untuk mencapai tujuan mereka dalam belajar bahasa Inggris. Sementara itu, proses yang paling sedikit diterapkan oleh siswa adalah kontrol perhatian. Dapat dilihat beberapa siswa yang memiliki perhatian dalam belajar. Mereka masih tidak bisa serius dan fokus dalam belajar bahasa Inggris.

\section{REFERENSI}

[1] Schunk H. Dale. Learning Theories. An Educational Perspective. The University of North Carolina at Greensboro. 2012. 
[2] Chambers, Ellie and Gregory, Marshall. Teaching and Learning. English Literature. Sage Publication Inc. 2006.

[3] Schunk H. Dale. Educational Psychologist,40 (2), 8594. Self-Regulated Learning: The Educational Legacy of Paul R. Pintrich. The University of North Carolina at Greensboro. 2000.

[4] Zumbrunn, Sharon. 2011. Encouraging Self-Regulated Learning in the Classroom: A Review of the Literature.

[5] Gay, L.R and Airisian, Peter. Educational Research: Competities for Analysis and Application. New Jersey: Prestice Hall. 2000.

[6] Merriam. Qualitative Research and Case Study Applications in Education. Revised and Expanded from: Case Study Research in Education. San Francisco: Jossey-Bass. 1998.

[7] Zimmerman J. Barry. Self-Regulated Learning and Academic Achievement. Theory, Research, and Practice. University of New York. 1989.

[8] Wang. C, Rolston, Joan. Understanding English Language Learners' Self Regulated Learning Strategies. U.S classroom and Home Communities. 2009. 